\title{
Comorbidity of Depression and Diabetes: In a Nutshell
}

\author{
Anisha Heeramun-Aubeeluck ${ }^{1}$, Zheng Lu ${ }^{1,2^{*}}$, Yanli Luo ${ }^{1}$ \\ ${ }^{1}$ Department of Psychosomatic Medicine, Tongji Hospital, Shanghai, China \\ ${ }^{2}$ Department of Adult Psychiatry, Shanghai Mental Health Center, Shanghai, China \\ Email: "luzheng@tongji.edu.cn
}

Received June $2^{\text {nd }}, 2012$; revised July $1^{\text {st }}, 2012$; accepted August $2^{\text {nd }}, 2012$

\begin{abstract}
Depression and diabetes mellitus (DM) have existed since ages. Yet, the etiologies of both diseases are unclear till date. However, the effects resulting from these diseases are well documented. Comorbidity of both disorders leads to increase disability and mortality rates. Besides presenting the epidemiological status of depression in DM, this review aims to highlight the different hypotheses governing the association of depression in DM and summarize the current trend in detection and management of depression. A high index of suspicion is required to detect depression in diabetic patients. There seems to be higher prevalence of depression in type 2 diabetes than in type 1 diabetes. Treatment should be tailored as per the individual needs and presence of comorbidity. Though there is no gold standard treatment for depressive diabetics, combinations of both pharmacological and non-pharmacological interventions are likely to improve outcomes. Selective serotonin reuptake inhibitors (SSRIs) and selective norepinephrine reuptake inhibitors (SNRIs) are preferred to conventional antidepressants. Collaborative care, psychoeducation and behavioral interventions are helpful in motivating patients to maintain treatment and improve psychological well-being and quality of life. Untreated depression in diabetics is costly to the health care and economic system as there is an increase in functional impairment and mortality rate. More efforts need to be made to effectively screen, diagnose and treat patients with comorbidity of diabetes and depression.
\end{abstract}

Keywords: Diabetes Mellitus; Depression; Management; Epidemiology

\section{Introduction}

Thomas Willis (1621-1675), a famous British physician, was the first to describe the relationship between depression and diabetes mellitus. He claimed that diabetes was a consequence of prolonged sorrows (Willis, 1675). This concept has flourished over the past three centuries and still remains a hotly debated subject amongst researchers in psychosomatic medicine. Though the concept of mind-body unity and the effect of psychological factors on the course of general medical conditions are the crux of psychosomatic medicine, the exact mechanisms underlying depression in diabetes mellitus (DM) is yet unknown. Depression as per the World Health Organization (WHO) represents a common mental disorder. It is characterized by depressed mood, loss of interest or pleasure, feelings of guilt or low self-worth, disturbed sleep or appetite, low energy, and poor concentration. On a darker side, it is also associated with increased risk of suicidal behavior estimated at approximately 850,000 lives per year (WHO, 2012). As per the Diagnostic and Statistical Manual of Mental Disorders, $4^{\text {th }}$ Edition, Text Revision (DSM-IV-TR), depression is classified as major depressive disorder. It can be further sub classified as single or recurrent episode. Degree of severity can also be specified and include mild, moderate and severe with/without psychotic features. The International Classification of Disease, $10^{\text {th }}$ Edition (ICD-10) subdivides depression into depressive episode and recurrent depressive episode. Each type can be graded depending on severity namely mild, moderate, and severe with or without psychotic symptoms. Furthermore, each diagnosis may be rated as with or without somatic syndrome. The diagnostic

${ }^{*}$ Corresponding author. criteria between ICD-10 and DSM-IV have some differences. Depressive episode as per ICD-10 should last at least 2 weeks and for mild, moderate and severe episodes a total of at least 6 , 8 and $>8$ symptoms must be met. Irrespective of the degree of the severity, ICD-10 requires any 2 of these core symptoms to be present:

1) Depressed mood sustained during almost all days for at least 2 weeks;

2) Loss of interest or pleasure;

3) Decreased energy or increased fatigability.

Recurrent depressive disorder (ICD-10) is diagnosed when there has been one previous episode (mild, moderate or severe) which lasted at least 2 weeks and time period between the previous episode and current one is a minimum of 2 months. The degree of severity is rated similar to depressive episode. On the other hand, as per DSM-IV-TR, major depressive disorder is characterized by a total of 5 or more symptoms lasting for a continuous 2 week period and a change from previous functioning. The core symptom of depression as per DSM-IV is one of these 2:

1) Depressed mood;

2) Loss of interest or pleasure.

Recurrent major depressive disorder (DSM-IV-TR) represents 2 more or previous episodes separated by a continuous 2 month period without depression. Severity is graded upon number of symptoms and degree of impairment in social and occupational functioning.

Dysthymia, which represents a chronic and milder depression is grouped under the depressive disorders constellation in DSM-IV-TR while in ICD-10, it represents persistent mood disorders. The diagnostic criteria for dysthymia in ICD-10 re- 
quire a minimum of 3 symptoms while DSM-IV-TR requires 2 symptoms. Though the duration is similar in both classification systems, the list of symptoms differ.

$\mathrm{DM}$ is a metabolic disorder of multiple etiologies characterized by chronic hyperglycemia with disturbances of carbohydrate, fat and protein metabolism resulting from defects in insulin secretion, insulin action, or both. DM can be broadly classified into four main categories namely:

1) Type 1 diabetes - onset usually in childhood and adolescence and results in $\beta$ cell destruction leading to absolute insulin deficiency.

2) Type 2 diabetes - due to progressive insulin secretory defect superimposed on insulin resistance; common in adult with obesity, unhealthy diets and lack of physical activity.

3) Gestational diabetes mellitus - diabetes diagnosed during pregnancy but which has not yet reached overt diabetes).

4) Other categories such as drug-induced, genetic disorders, and exocrine pancreatic disorders.

The diagnostic criteria for diabetes is either one of the following:

1) $\mathrm{A} 1 \mathrm{C} \geq 6.5 \%$. The test should be performed in a laboratory using a method that is National Glycohemoglobin Standardization Program (NGSP) certified and standardized to the Diabetes Control and Complications Trial (DCCT) reference assay.

2) $\mathrm{FPG} \geq 126 \mathrm{mg} / \mathrm{dL}(7.0 \mathrm{mmol} / \mathrm{L})$. Fasting is defined as no caloric intake for at least 8 hours.

3) 2 hour plasma glucose $\geq 200 \mathrm{mg} / \mathrm{dL}$ ( $11.1 \mathrm{mmol} / \mathrm{L})$ during an Oral Glucose Tolerance Test (OGTT). The test should be performed as described by the WHO, using a glucose load containing the equivalent of $75 \mathrm{~g}$ anhydrous glucose dissolved in water.

The diagnosis of DM itself can be a major life stress event to an individual. Vulnerable subjects fail to cope with the complex and wide-arrayed physical and mental accommodations required. Consequently, the affected individual may lose interest or lack energy in maintaining his diabetic management. Unhealthy eating habits are also frequent and may contribute to jeopardizing the control of DM. Risks of suicide through insulin overdose may also increase due to easy access to insulin. Furthermore, the complications of DM such as retinopathy, neuropathy and nephropathy overwhelm the already vulnerable subjects. These scenarios accentuate the seriousness of detecting and treating depression in DM.

Besides presenting the epidemiological status of depression in DM, this review aims to highlight the different hypotheses governing the association of depression in DM and summarize the current trend in detection and management of depression.

\section{Epidemiological Status of Depression and DM}

As per Greden et al. (2003) depression was a serious global health issue affecting approximately 340 million people worldwide. The WHO survey conducted in 2000 , depression was the $4^{\text {th }}$ leading factor to global burden of disease in women while in men it was on $7^{\text {th }}$ position (Ustun et al., 2004). The lifetime prevalence of depression in different countries varied: US $16.6 \%$, Europe 14\%, Asia-Pacific 1.1\% - 19.9\% and South Africa 9.7\% (Kessler et al., 2005; Alonso et al., 2005; Chui, 2004; Tomlinson et al., 2009).

A meta-analytical study had previously reported $11 \%$ of people with DM suffered from depression and that $31 \%$ of them had clinically relevant depression (Anderson et al., 2001).
In a more recent systematic review the co-existence of DM and depression was confirmed (Egede \& Ellis, 2010). Interestingly rates for undiagnosed depression in DM patients as per the study conducted by $\mathrm{Li}$ et al. (2008) equaled to $45 \%$. The WHO World Health Survey studied adults aged 18 and above in 60 different countries worldwide and concluded that 1 year prevalence for depression in diabetes was 2\% (Moussavi et al., 2007). TA systematic review reported the prevalence of depression in young adults with type 1 diabetes as inconclusive (Johnson et al., 2012). On the other hand, a meta-analytic review supported claim for raised rate of depression in type 2 diabetes, which is also the most common type of diabetes (Ali et al., 2006).

The International Diabetes Federation (IDF) estimated around 280 million people with DM in 2010 and this figure is thought to increase to 439 million in 2030 (IDF, 2009). DM currently holds the $7^{\text {th }}$ place in cause of death (Murphy et al., 2012). With depression superimposed in DM, the mortality rate is likely to increase. Furthermore, there is evidence showing that depression was significantly associated with a wide range of diabetes complications with effect sizes of .17 - .32 (Groot et al., 2001). In sum, untreated depression is one of contributing factors for increased mortality rate in DM.

\section{Risk Factors for Depression in DM}

The feeling of "sadness" is a normal emotional reaction elicited by many events such as loss and disease. This reaction produces a variety of effects on the subject affecting his physical appearance, physical and mental functioning (neurobiological, hormonal and psychological) as well as his family, social and occupational activities and relationships (Levenson, 2001). Genetic predisposition and/or childhood adverse events leading to maladaptive coping strategies increase the vulnerability of a person to depression. Coupled with multiple or recurrent stressful events, the subject with the above characteristics has a higher probability of developing depression. Furthermore, vulnerability might also be increased due to unhealthy life style or behavior such as obesity, inadequate exercise, poor diet and smoking. There are several predisposing factors for comorbidity of depression and diabetes and include:

1) Age-A Canadian survey suggested that prevalence of depression in diabetic patients is higher in the younger age group (20 - 39 years) as compared to the middle aged groups (40 - 64 years). This finding has been supported by study conducted by Katon et al. (2004). In a survey of However, Trief (2007) argued that elderly (above 65 years) were also at high risk. A study in elderly Spanish revealed that diabetes was associated with an increased risk of prevalent (odds ratio $=1.47$ ) and incident (odds ratio $=1.40$ ) depression. Another survey in elderly Chinese on Homg Kong found that of that $26 \%$ of elderly had diabetes and elevated depressive symptoms (Chou \& Chi., 2005).

2) Gender - The impact of depression in diabetes is thought to be higher in females. A large prospective women cohort conducted in 11 US states found that women with diabetes and comorbid depression had increased mortality rate (95\% C.I of 3.11) (Pan et al., 2011). However, it should be pointed out that generally fewer males than females seek treatment for depression. Furthermore, depression in males is more likely to produce irritability, anger or violent behavior rather than depressed 
mood and thus depression might be missed on screening as irritability/anger are not hallmark features of depression.

3) Ethnicity-Li et al. (2009) in a large standardized telephone survey covering 50 states in the US found a difference of 25 fold in rates prevailing among ethnic subgroups (lowest: Asian $1.1 \%$ and highest: $27.8 \%$ in American Indians/Alaska Natives). Another study found increased depressive symptoms in African Americans (Kogan et al., 2007).

4) Other factors - Never married and lower education level had also been reported to influence the status of depression in DM (Katon et al., 2004). Another large population-based study demonstrated that depression in type $2 \mathrm{DM}$ was associated with lower level of education, lack of physical activity, physical impairment and somatic complaints whilst type 1 DM was correlated with physical impairment and lower levels of education (Engum et al., 2005). Few studies have focused on the interrelationship between depression and DM in pregnancy. Kozhimannil et al. (2009) reported a two fold increase in odds ratio of perinatal depression (ICD 9 code) in women with gestational diabetes. However, another study conducted by Katon et al. (2011) showed that antenatal depression (DSM-IV) and gestational diabetes was not independently associated.

\section{Causal Links between Depression and DM}

As described in the previous section, vulnerable individuals have difficulties ending the normal process of sadness or grief and thus are predisposed to experience depression. Figure 1 summarizes the hypothesized pathways to depression.

The exact etiologies and mechanisms behind depression in DM are yet unknown. However, research in that field has yielded some hypotheses regarding the relationship between depression and DM. The most popular theory states that the link between depression and DM is bidirectional, that is, DM may predispose or induce depression and depression may predispose or induce DM. A meta-analytic review examining the

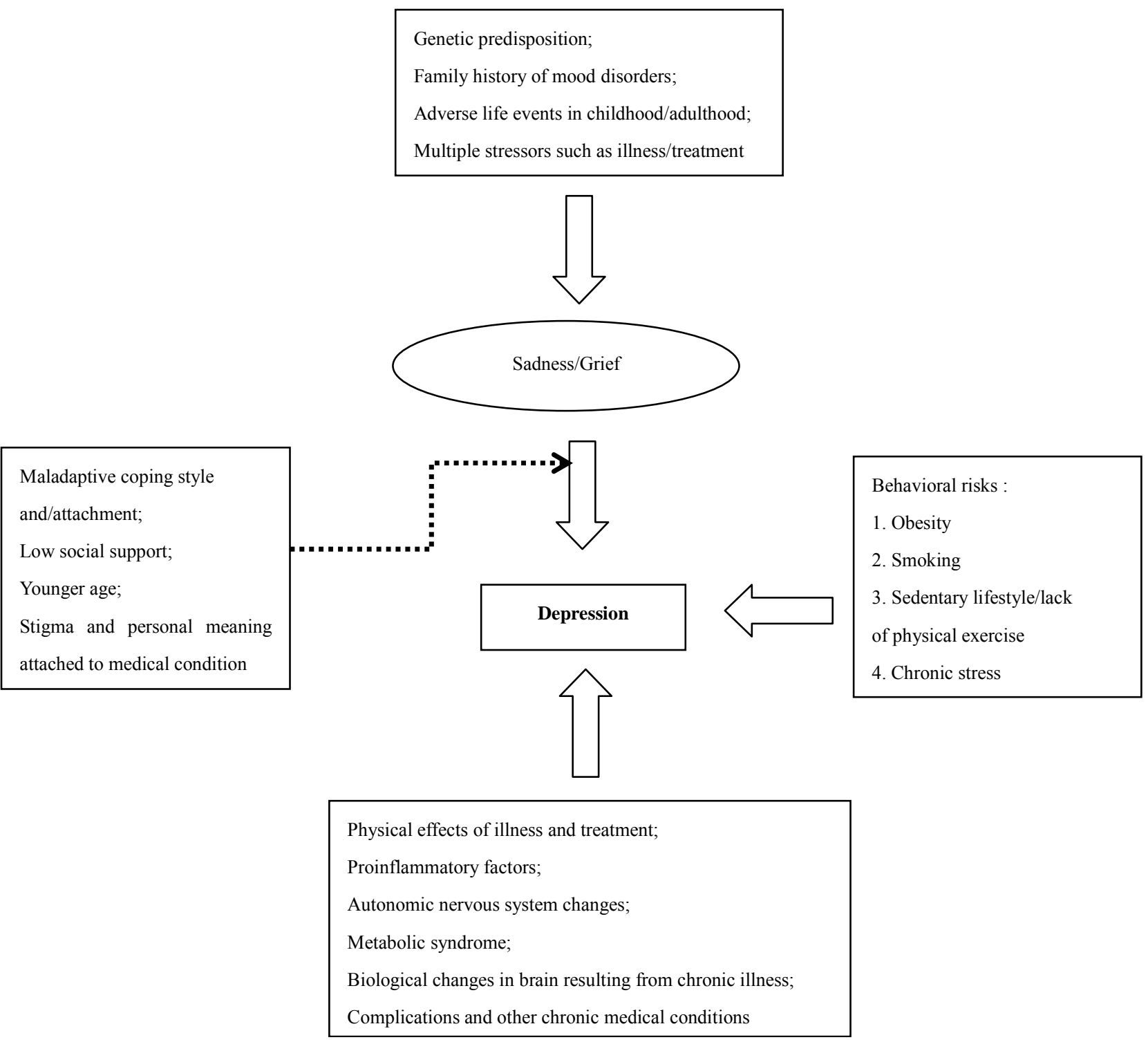

Figure 1.

Factors causing and influencing depression (Peveler et al., 2002; Katon, 2003). 
relationship between depression and DM from 1950-2007 demonstrated that depression was correlated with $60 \%$ increase in type 2 diabetes whilst type 2 DM shared a correlation of $15 \%$ with depression (Mezuk et al., 2008). Kohl et al. (2006) claim that depression is not only a consequence of DM but might also predispose to onset of type $2 \mathrm{DM}$. After controlling for sociodemographic and other clinical health variables, depresssion was an independently associated with onset of type 2 diabetes (Musselman et al., 2003; Williams et al., 2006). On the other hand, depression might also predict the number and severity of diabetic complications (Groot et al., 2001; Ludman et al., 2004).

Proposed biological links between depression and DM are illustrated in Figures 2 and 3.

\section{Screening for Depressive Diabetics}

The need to detect depression in diabetic patients is important in order to help them achieve a better quality of life. In a primary care setting, patients with family history of mood disorders, previous history of depression or anxiety or history of substance abuse should alert the physician of possibility of depression (Lustman \& Clouse, 1997). Other symptoms that might tip off the probability of depression are unexplained hyperglycemia or hypoglycemia and their related symptoms despite appropriate pharmacotherapy, persistent somatic complaints, chronic pain and sexual dysfunction. These patients are good candidates for screening for depression.

A recent review on screening of depression in diabetic patients suggested that the following scales are the most popular screening instruments: the Center for Epidemiological Studies-Depression Scale (CES-D), the Beck Depression Inventory (BDI), and the Patient Health Questionnaire (PHQ-9) (van der Feltz-Cornelis, 2011). However, with regard to detecting depression in DM, data on the validity and reliability of these screening tools as well as their cultural applicability are scarce.

Evidence suggested that the CES-D was the best predictor of depression in type 2 diabetes (McHale et al., 2008). Furthermore, as there was an elevated association between symptoms of depression and diabetes-related distress, the CES-D proved to be efficient in distinguishing between depressive and non-depressive symptoms. In clinical setting, use of the BDI was likely to detect more than $70 \%$ of the patients with depression while providing a sensitivity of greater than $70 \%$ (Lustman \&

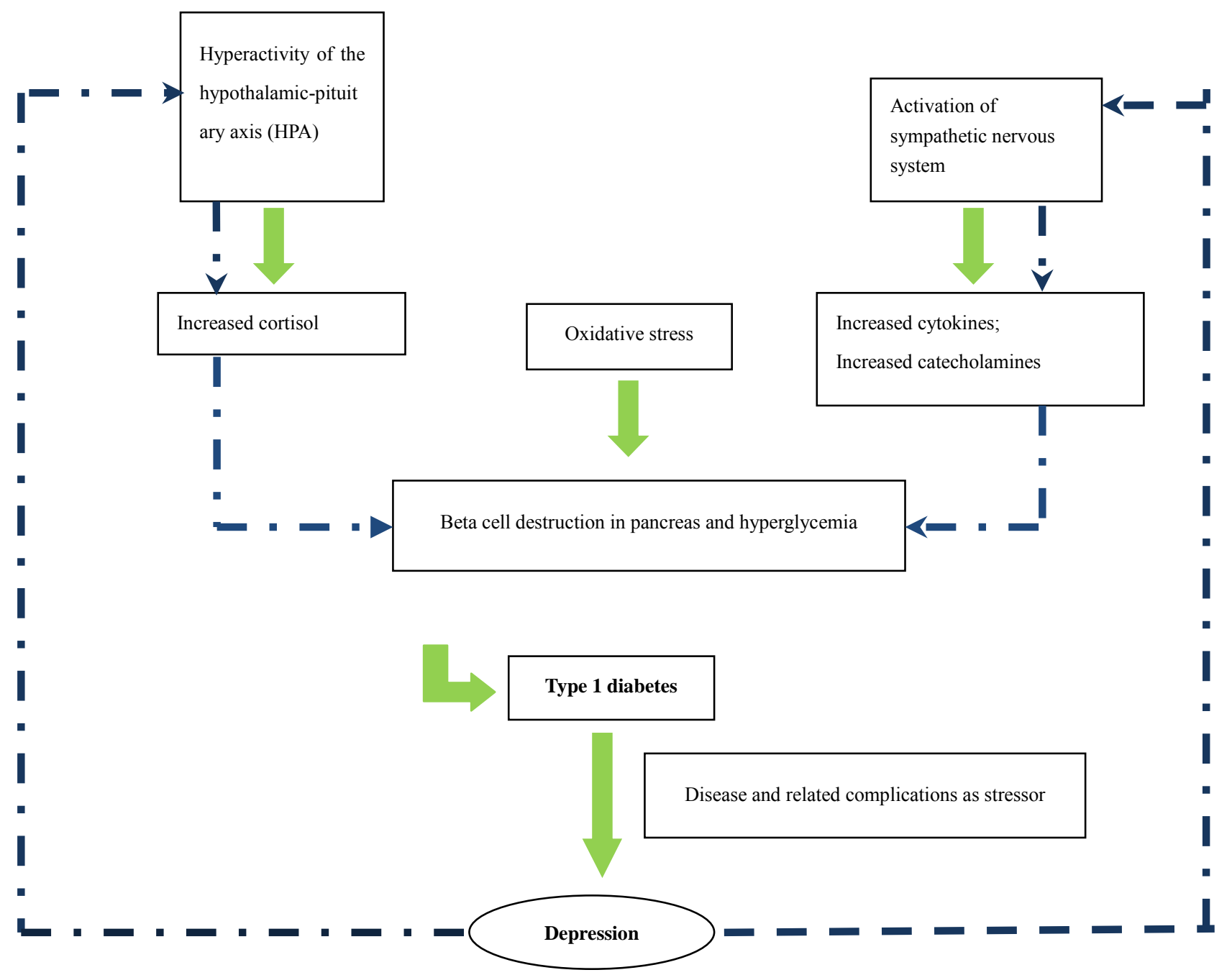

Figure 2.

Biological links between depression and type 1diabetes (Ref: korczak et al., 2011). 


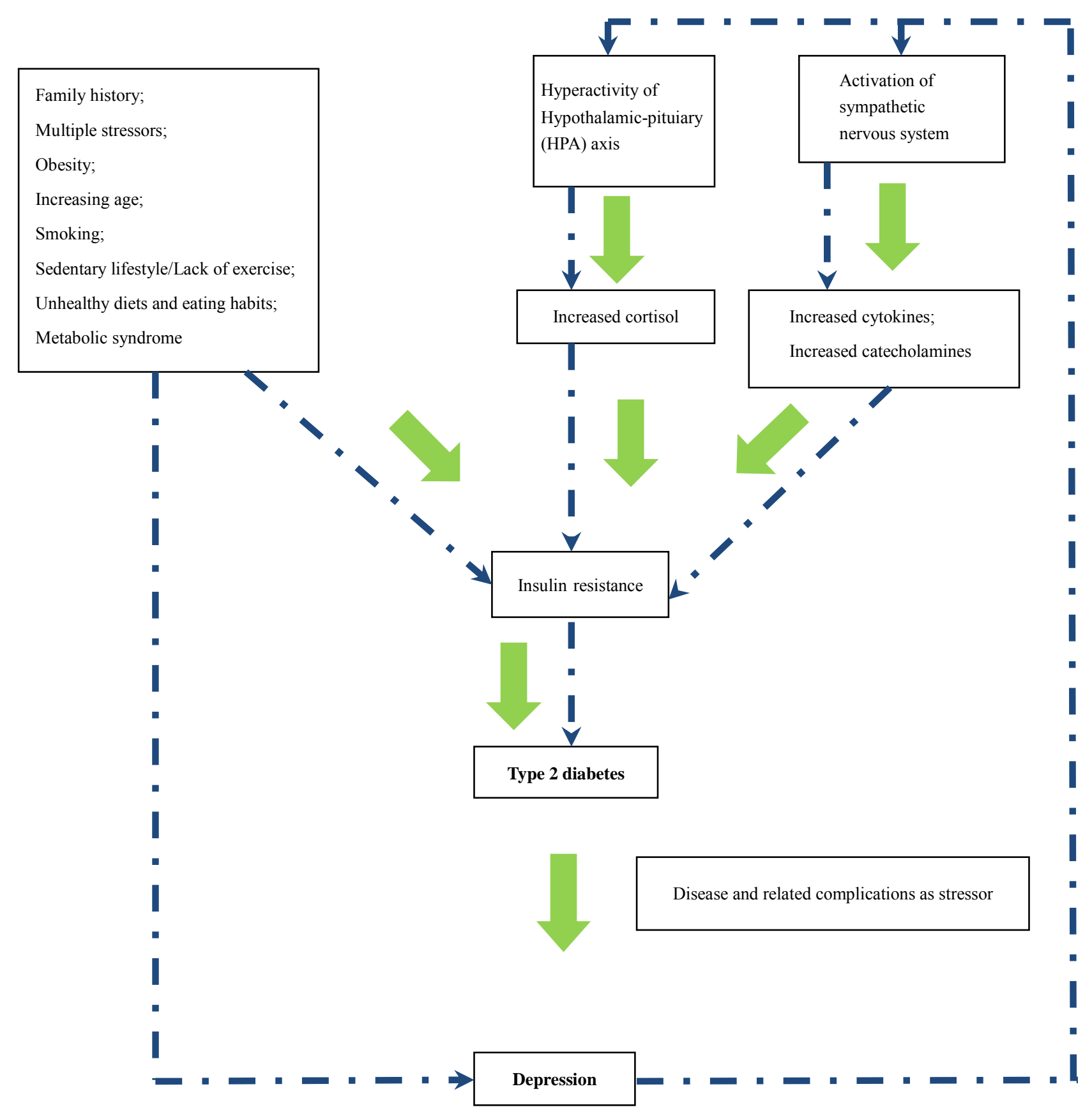

Figure 3.

Summary of causal links between type 2 diabetes and depression (Ref. Champani et al., 2010).

Clouse, 2004). The PHQ-9 is based on the DSM-IV major depressive disorder criteria. The advantages of the PHQ-9 include availability in 27 languages, brief, and also measurement of the severity of depression. Van Steenbergen-Weijenburg et al. (2010) found that the PHQ-9 was more accurate than the MINI (Mini International Neuropsychiatric Interview) in assessing depression in type 2 diabetes. Other screening instruments comprise of the following scales: the World Health Organization Five Wellbeing questionnaire (WHO-5), the Psychosomatic Evaluation of Problem areas in Diabetes (PAID), the Hamilton rating Scale for Depression (HAM-D), and the two screening questions.
It should be stressed that screening instruments are not diagnostic of depressive disorder and a thorough interview needs to be conducted for a formal diagnosis of depression. The diagnostic criteria for depression and diabetes have been summarized in section 1 .

\section{Clinical Goals and Treatment Strategies}

Irrespective of the age group of patients, the management of DM consists of these general goals:

1) Regulate blood glucose, blood pressure and lipid profile and their associated symptoms; 
2) Identify and treat macrovascular and microvascular complications;

3) Effective self-management by patients and

4) Improve or stabilize the general health status of patients.

However, in practice only a small percentage of patients are able to reach the desired clinical goals. Various factors are thought to be implicated such as patient's beliefs about disease, the severity of the disease, comorbid disorders, financial and economic status and availability of support. Qaseem et al. (2007) recommend that glycemic control should be based upon severity of disease and risk of complications, comorbidity, life expectancy, and patient's preferences - thus treatment goals ought to be individualized.

Diabetes coupled with depression tends to increase the disease burden and functional impairment. As mentioned above primary care physicians need to have a high index of suspicion in detecting underlying depression in diabetic patients. In a longitudinal assessment of 998 adults with type 2 diabetes, Chui et al. (2010) found that general health behaviors (physical exercise, weight control, and smoking) explained $13 \%$ of the depression-hyperglycemic link. The association between depression and hyperglycemia has been replicated in other studies (Rush et al., 2008; Katon et al., 2004). Interestingly, Lustman et al., (2005) failed to establish diabetes self-care as a mediator between depression and hyperglycemia in type 1 diabetes. Nonetheless, lifestyle and health behaviors modification are essential in the management of depressive diabetic patients. Proposed strategies include:

1) Weight loss and exercise. Older patients are more likely to successfully meet these goals (Diabetes Prevention Program Research Group, 2004). Other beneficial effects of exercise include reduced abdominal adiposity, improved lipid profile, enhanced cardiac function and coronary blood flow and decrease blood pressure. All these factors are directly and indirectly related to diabetes and its complications;

2) Reducing or quitting cigarette smoking and alcohol consumption;

3) Healthy diet: Increasing consumption of vegetables and fruits, reducing intake of fatty foods, monitoring caloric intake based on height and occupational requirement. Aggressive diets can lead to disastrous consequences in patient with low hypoglycemic awareness. Furthermore, the adverse effects of tight glycemic control is said to increase exponentially with age.

Treatment can be pharmacological, psychotherapeutic or combined interventions. A recent meta-analysis has deemed it effective to treat depression in diabetic patients (van der FeltzCornelis et al., 2010). The role of antidepressant and whether the class of antidepressant used had an influence on the glycemic control was not clarified in the meta-analysis. Echeverry et al. (2009) found significant association between treatment of depression with sertraline and decrease in A1C levels as well as systolic pressure in a low income Hispanic and African American sample. The Pathways study, on the other hand, in its one year study did not find significant differences in A1C levels in between treatment group for depression and placebo group (Katon et al., 2004). Concern has also been raised regarding the role of antidepressant in causing DM. A large well-conducted trial found significant association between antidepressant use for depression and diabetes was nullified by lifestyle/risk factors (Wilkins \& Sambamoorthi, 2011). Another large trial in middle-aged patients also supported the theory of no causal relationship between antidepressant and DM (Kivimäki et al.,
2011). Interestingly, in a large sample of multi-ethnic postmenopausal women, the use of antidepressants in women with longstanding or elevated depressive symptoms was significantly associated with a higher risk of DM (Ma et al., 2011).

A review on antidepressant use in DM showed that selective serotonin reuptake inhibitors (SSRIs) such as fluoxetine, paroxetine, citalopram and sertraline not only improved depression but also helped in reducing glucose levels while nortriptyline (norepinephrine reuptake inhibitor, NRI) worsened the glucose control (Goodnick, 2001). Studies on conventional antidepressants have shown that they are liable to increase the risk of metabolic syndrome and hence DM (van Reedt Dortland et al., 2010; Mcintyre et al., 2010). Another antidepressant that has proved to be beneficial in comorbid depression and DM is milnacipran which is a serotonin and norepinephrine reuptake inhibitor (SNRI) (Hoffman, 2010). Depressive diabetic patients with sexual dysfunction might benefit from the use of bupropion which is a norepinephrine-dopamine reuptake inhibitor (Sayuk et al., 2011). Inadequate response to antidepressants in depressive type 2 diabetics might benefit from treating co-existing symptoms such as pain and impairment (Anderson et al., 2010).

Regarding psychotherapeutic interventions, as evidenced by findings of a systematic review, they helped improve the severity of depression and had limited effects on the reduction of A1C levels (Wang et al., 2008). Nevertheless, studies which had focused on behavioral modifications or collaborative care in depressive diabetics had improved outcomes and adherence to medications. A combination of both pharmacotherapy and psychotherapeutic interventions might lead to better outcome measures and quality of life. Unfortunately, in real life, patients with new-onset depression and medical comorbidities might not be receiving adequate treatment (Gill et al., 2010).

\section{Conclusion}

Functional impairment as well as adverse effects caused by comorbidity of DM and depression is a fact. Due to the increasing number of both DM and depression and their hypothesized associations, identification and treatment is a must. However, since DM has its own related diabetes-distress syndrome, diagnosis is tricky. A high index of suspicion is required as at times patients are unaware of their latent depression. Another difficulty likely to be encountered is that many diabetic patients have depressive symptoms which do not meet the criteria for a diagnosis of depression as per DSM-IV-TR or ICD-10. Furthermore, there is growing evidence that many patients given the diagnosis of depression are in fact having Bipolar II disorder. Unfortunately, research on comorbidity of Bipolar II and diabetes is scarce. Since antidepressants are not the first choice for managing mild depression, patients with either subsyndromal depression or mild depression are more likely to benefit from added non-pharmacological approaches such as psychoeducation, coping skills strategies and behavioral interventions to their regular treatment. These strategies could also be added to the treatment of diabetic patients with a formal diagnosis of depression. Whatever strategies employed, they should be individualized to the person. From a different angle, in the long run, treated depressive diabetics might reduce the economic burden of these 2 diseases by reducing complications and functional impairment. 


\section{REFERENCES}

Ali, S., Stone, M. A., Peters, J. L., Davies, M. J., \& Khunti, K. (2006). The prevalence of co-morbid depression in adults with Type 2 diabetes: A systematic review and meta-analysis. Diabetic Medicine, 23, 1165-1173. doi:10.1111/j.1464-5491.2012.03721.x

Alonso, J. et al. (ESEMeD/MHEDEA 2000 Investigators) (2004). Project prevalence of mental disorders in Europe: Results from the European Study of the Epidemiology of Mental Disorders (ESEMeD) project. Acta Psychiatrica Scandinavica Suppletum, 420, 21-27.

Anderson, R. J., Freedland, K. E., Clouse, R. E., \& Lustman, P. J. (2001). The prevalence of comorbid depression in adults with diabetes: A meta-analysis. Diabetes Care, 24, 1069-1078.

doi:10.2337/diacare.24.6.1069

Anderson, R. J., Gott, B. M., Sayuk, G. S., Freedland, K. E., \& Lustman, P. J. (2010). Antidepressant pharmacotherapy in adults with type 2 diabetes. Diabetes Care, 33, 485-489. doi:10.2337/dc09-1466

Champaneri, S., Wand, G. S., Malhotra, S. S., Casagrande, S. S., \& Golden, S. H. (2010). Biological basis of depression in adults with diabetes. Current Diabetes Reports, 10, 396-405.

Chiu, C. J., Wray, L. A., Beverly, E. A., \& Dominic, O. G. (2010). The role of health behaviors in mediating the relationship between depressive symptoms and glycemic control in type 2 diabetes: A structural equation modeling approach. Social Psychiatry and Psychiatric Epidemiology, 45, 67-76. doi:10.1007/s00127-009-0043-3

Chou, K. L, \& Chi, I. (2005) Prevalence of depression among elderly Chinese with diabetes. International Journal of Geriatric Psychiatry, 20, 570-575. doi:10.1002/gps. 1328

Chui, E. (2004). Epidemiology of depression in the Asia Pacific region. Australasian Psychiatry, 12, S4-S10.

De Jonge, P., Roy, J. F., Saz, P., Marcos, G., \& Lobo, A. (ZARADEMP Investigators) (2006). Prevalent and incident depression in community-dwelling elderly persons with diabetes mellitus: Results from the ZARADEMP project. Diabetologia, 49, 2627-2633. doi:10.1007/s00125-006-0442-x

Echeverry, D., Duran, P., Bonds, C., Lee, M., \& Davidson, M. B. (2009). Effect of pharmacological treatment of depression on A1C and quality of life in low-income Hispanics and African Americans with diabetes: A randomized, double-blind, placebo-controlled trial. Diabetes Care, 32, 2156-2160. doi:10.2337/dc09-0785

Egede, L. E., \& Ellis, C. (2010). Diabetes and depression: Global perspectives. Diabetes Research and Clinical Practice, 87, 302-312. doi:10.1016/j.diabres.2010.01.024

Engum, A., Mykletun, A., Midthjell, K., Holen, A., \& Dahl, A. (2005). Depression and diabetes: A large population-based study of sociodemographic, lifestyle, and clinical factors associated with depresssion in type 1 and type 2 diabetes. Diabetes Care, 28, 1904-1909. doi:10.2337/diacare.28.8.1904

Gill, J. M., Klinkman, M. S., \& Chen, Y. X. (2010). Antidepressant medication use for primary care patients with and without medical comorbidities: A national Electronic Health Record (EHR) network study. Journal of the American Board of Family Medicine, 23, 499508. doi:10.3122/jabfm.2010.04.090299

Goodnick, P. J. (2001). Use of antidepressants in treatment of comorbid diabetes mellitus and depression as well as in diabetic neuropathy. Annals of Clinical Psychiatry, 13, 31-41. doi:10.3109/10401230109147127

Greden, J. F. (2003). Physical symptoms of depression: Unmet needs. Journal of Clinical Psychiatry, 64, 5-11.

Groot, M. D., Anderson, R., Freedland, K. E., Clouse, R. E., \& Lustman, P. J. (2001). Association of depression and diabetes complications: A meta-analysis. Psychosomatic Medicine, 63, 619-630.

Hoffman, P. (2010). Treatment of patients with comorbid depression and diabetes with metformin and milnacipran. Neuropsychiatric Disease and Treatment, 6, 9-15.

International Diabetes Federation (2009). Diabetes Atlas (4 ${ }^{\text {th }}$ ed.). Brussels: International Diabetes Federation.

Johnson, B., Eiser C., Young, V., Brierley, S., \& Heller, S. (2012). Prevalence of depression among young people with Type 1 diabetes: A systematic review. Diabetic Medicine, Epub ahead of print. doi:10.1111/j.1464-5491.2012.03721.x
Katon, W. J. (2003). Clinical and health services relationships between major depression, depressive symptoms, and general medical illness. Biological Psychiatry, 54, 216-226. doi:10.1016/S0006-3223(03)00273-7

Katon, W., Von kroff, M., Ciechanowski, P., Russo, J., Lin, E., Simon, G., Ludman, E., Walker, E., Bush, T., \& Young, B. (2004). Behavioural and clinical factors associated with depression among individuals with diabetes. Diabetes Care, 27, 914-920. doi:10.2337/diacare.27.4.914

Katon, W. J., Von Korff, M., Lin, E. H. B., Simon, G., Ludman, E., Russo, J., Ciechanowski, P., Walker, E., \& Bush, T. (2004). The pathways study. A randomized trial of collaborative care in Patients with diabetes and depression. Archives of General Psychiatry, 61, 1042-1049. doi:10.1001/archpsyc.61.10.1042

Katon, J. G., Russo, J., Gavin, A. R., Melville, J. L., \& Katon, W. J. (2011). Diabetes and depression in pregnancy: Is there an association? Journal of Women's Health, 20, 983-989. doi:10.1089/jwh.2010.2662

Kessler, R. C., Berglund, P., Demler, O., Jin, R., Merikangas, K. R., \& Walters, E. E. (2005) Lifetime prevalence and age-of-onset distributions of DSM-IV disorders in the national comorbidity survey replication. Archives of general psychiatry, 62, 593-602. doi:10.1001/archpsyc.62.6.593

Kivimäki, M., Batty, G. D., Jokela, M., Ebmeier, K. P., Vahtera, J., Virtanen, M., Brunner, E. J., Tabak, A. G., Witte, D. R., Kumari, M., Singh-Manoux, A., \& Hamer, M. (2011). Antidepressant medication use and risk of hyperglycemia and diabetes mellitus-A noncausal association? Biological Psychiatry, 70, 978-984.

Knol, M. J., Twisk, J. W., Beekman, A. T., Heine, R. J., Snoek, F. J., \& Pouwer, F. (2006). Depression as a risk factor for the onset of type 2 diabetes mellitus. A meta-analysis. Diabetologia, 49, 837-845. doi:10.1007/s00125-006-0159-x

Kogan, S. M., Brody, G. H., Crawley, C., Logan, P., \& Murry, V. M. (2007). Correlates of elevated depressive symptoms among rural African American adults with type 2 diabetes. Ethnicity \& Disease, 17, 106-112.

Korczak, D. J., Pereira, S., Koulajian, K., Matejcek, A., \& Giacca, A. (2011). Type 1 diabetes mellitus and major depressive disorder: evidence for a biological link. Diabetologia, 54, 2483-2493.

Kozhimannil, K. B., Pereira, M. A., \& Harlow, B. L. (2009). Association between diabetes and perinatal depression among low-income mothers. Journal of the American Medical Association, 301, 842847. doi:10.1001/jama.2009.201

Levenson, J. L. (2001). Textbook of psychosomatic medicine. Arlington, VA: American Psychiatric Publishing, 193.

Li, C., Ford, E. S., Strine, T. W., \& Mokdad, A. H. (2008). Prevalence of depression among US adults with diabetes: findings from the 2006 behavioral risk factor surveillance system. Diabetes Care, 31, 105107. doi: $10.2337 / \mathrm{dc} 07-1154$

Li, C., Ford, E. S., Zhao, G., Ahluwalia, I. B., Pearson, W. S., \& Mokdad, A. H. (2009). Prevalence and correlates of undiagnosed depression among US adults with diabetes: The Behavioral Risk Factor Surveillance System. Diabetes Research and Clinical Practice, 83, 268-279. doi:10.1016/j.diabres.2008.11.006

Lustman, P. J., \& Clouse, R. E (1997). Identifying depression in adults with diabetes. Clinical Diabetes, 15, 78-81.

Ludman, E. J., Katon, W., Russo, J., Von Korff, M., Simon, G., Ciechanowski, P., Lin, E., Bush, T., Walker, E., \& Young, B. (2004). Depression and diabetes symptom burden. General Hospital Psychiatry, 26, 430-436. doi:10.1016/j.genhosppsych.2004.08.010

Lustman, P. J., \& Clouse, R. E. (2004). Section III: Practical Considerations in the management of depression in diabetes. Diabetes Spectrum, 17, 160-166. doi:10.2337/diaspect.17.3.160

Lustman, P. J., Clouse, R. E., Ciechanowski, P. S., Hirsch, I. B., \& Freedland, K. E. (2005). Depression-related hyperglycemia in type 1 diabetes: A mediational approach. Psychosomatic Medicine, 67, 195 199. doi:10.1097/01.psy.0000155670.88919.ad

Ma, Y., Balasubramanian, R., Pagoto, S. L., Schneider, K. L., Culver, A. L., Olendzki, B., Tinker, L., Liu, S., Safford, M., Sepavich, D. M., Rosal, M.C., Ockene, J. K., Carnethon, M., Zorn, M., \& Hébert, J. R. (2011). Elevated depressive symptoms, antidepressant use, and diabetes in a large multiethnic national sample of postmenopausal wo- 
men. Diabetes Care, 34, 2390-2392. doi:10.2337/dc11-1223

McHale, M., Hendrikz, J., Dann, F., \& Kenardy, J. (2008). Screening for depression in patients with diabetes mellitus. Psychosomatic Medicine, 70, 869-874.

Mclntyre, R. S., Park, K. Y., Law, C. W. Y., Sultan, P., Adams, A., Lourenco, M. T., Lo, A. K. S., Soczynska, J. K., Woldeyohannes, H., Alsuwaidan, M., Yoor, J., \& Kennedy, S. H. (2010). The association between conventional antidepressants and the metabolic syndrome. A Review of the evidence and clinical implications. CNS Drugs, 24, 741-763. doi:10.2165/11533280-000000000-00000

Mezuk, B., Eaton, W. W., Albrecht, S., \& Golden, S. H. (2008). Depression and type 2 diabetes over the lifespan: A meta-analysis. Diabetes Care, 31, 2383-2390. doi:10.2337/dc08-0985

Moussavi, S., Chatterji, S., Verdes, E., Tandon, A., Patel, V., \& Ustun, B. (2007). Depression, chronic diseases, and decrements in health: Results from the World Health Surveys. Lancet, 370, 851-858. doi:10.1016/S0140-6736(07)61415-9

Murphy, S. L., Xu, J., \& Kochanek, K. D. (2012). Deaths preliminary data for 2010. National Vital Statistics Reports, 60, 1-68.

Musselman, D. L., Betan, E., Larsen, H., Phillips, L. S. (2003). Relationship of depression to diabetes types 1 and 2: Epidemiology, biology, and treatment. Biological Psychiatry, 54, 317-329. doi:10.1016/S0006-3223(03)00569-9

Pan, A., Lucas, M., Sun, Q., van Dam, R. M., Franco, O. H., Willett, W. C., Manson, J. E., Rexrode, K. M., Ascherio, A., \& Hu, F. B. (2011). Increased mortality risk in women with depression and diabetes mellitus. Archives of General Psychiatry, 68, 42-50. doi:10.1001/archgenpsychiatry.2010.176

Peveler, R., Carson, A., \& Rodin, G. (2002). ABC of psychological medicine: Depression in medical patients. British Medical Journal, 325, 149-152. doi:10.1136/bmj.325.7356.149

Qaseem, A., Vijan, S., Snow, V., Cross, J. T., Weiss, K. B., \& Owens, D. K. (Clinical Efficacy Assessment Subcommittee of the American College of Physicians) (2007). Glycemic control and type 2 diabetes mellitus: the optimal hemoglobin A1C targets. A guidance statement from the American College of Physicians. Annals of Internal Medicine, 147, 417-422.

Rush, W. A., Whitebird, R. R., Rush, M. R., Solberg, L. I., \& O’Conner, P. J. (2008). Depression in patients with diabetes: Does it impact clinical goals? Journal of the American Board Family Medicine, 21, 392-397. doi: 10.3122/jabfm.2008.05.070101

Sayuk, G. S., Gott, B. M., Nix, B. D., \& Lustman, P. J. (2011). Improvement in sexual functioning in patients with type 2 diabetes and depression treated with bupropion. Diabetes Care, 34, 332-334. doi: $10.2337 / \mathrm{dc} 10-1714$

The Diabetes Prevention Program Research Group (2004). Achieving weight and activity goals among Diabetes Prevention Program Lifestyle participants. Obesity Research, 12, 1426-1434.

doi:10.1038/oby.2004.179
Tomlinson, M., Grimsrud, A. T., Stein, D. J., Williams, D. R., \& Myer, L. (2009). The epidemiology of major depression in South Africa: Results from the South African stress and health study. South African Medical Journal, 99, 367-373.

Ustun, T. B., Ayuso-Mateos, J. L., Chatterji, S., Mathers, C., \& Murray, C. J. (2004). Global burden of depressive disorders in the year 2000. British Journal of Psychiatry, 184, 386-392. doi:10.1192/bjp.184.5.386

van der Feltz-Cornelis, C. M., Nuyen, J., Stoop, C., Chan, J., Jacobson, A. M., Katon, W., Snoek, F., \& Sartorius, N. (2010). Effect of interventions for major depressive disorder and significant depressive symptoms in patients with diabetes mellitus: A systematic review and meta-analysis. General Hospital Psychiatry, 32, 380-395.

doi:10.1016/j.genhosppsych.2010.03.011

van der Feltz-Cornelis, C. M. (2011). Depression in diabetes mellitus: To screen or not to screen? A patient-centred approach. British Journal of Diabetes \& Vascular Disease, 11, 276-281.

van Reedt Dortland, A. K. B., Giltay, E. J., van Veen, T., Zitman, F. G., \& Penninx, B. W. J. H. (2010). Metabolic syndrome abnormalities are associated with severity of anxiety and depression and with tricyclic antidepressant use. Acta Psychiatrica Scandinavica, 122, 30-39. doi:10.1111/j.1600-0447.2010.01565.x

Van Steenbergen-Weijenburg, K. M., de Vroege, L., Ploeger, R. R., Brals, J. W., Vloedbeld, M. G., Veneman, T. F., Hakkaart-van Roijen, L., Rutten, F. F., Beekman, A. T., \& van der Feltz-Cornelis, C. M. (2010). Validation of the PHQ-9 as a screening instrument for depression in diabetes patients in specialized outpatient clinics. BMC Health Services Research, 12, 235. doi:10.1186/1472-6963-10-235

Wang, M. Y., Tsai, P. S., Chou, K. R., \& Chen, C. M. (2008). A systematic review of the efficacy of non-pharmacological treatments for depression on glycaemic control in type 2 diabetics. Journal of Clinical Nursing, 17, 2524-2530. doi:10.1111/j.1365-2702.2008.02301.x

Wilkins T. L., \& Sambamoorthi, U. (2011). Antidepressant use, depression, lifestyle factors and new-onset diabetes. International Clinical Psychopharmacology, 26, 159-168. doi:10.1097/YIC.0b013e328342ce31

Williams, M. M., Clouse, R. E., \& Lustman, P. J. (2006). Treating depression to prevent diabetes: Understanding depression as a medical complication. Clinical Diabetes, 24, 79-86. doi:10.2337/diaclin.24.2.79

Willis, T. (1675). Pharmaceutice rationalis sive diabtriba demedicamentorum operantionibus in humano corpore. Oxford: MDCLXXV.

World Health Organization (2012). URL (last checked 22 July 2012). http://www.who.int/mental_health/management/depression/definitio $\mathrm{n} / \mathrm{en} /$

Zhao, W., Chen, Y., Lin, M., \& Sigal, R. J. (2006). Association between diabetes and depression: Sex and age differences. Public Health, 120, 696-704. doi:10.1016/j.puhe.2006.04.012 